Original Article

\title{
HIGH-PERFORMANCE THIN LAYER CHROMATOGRAPHY (HPTLC) FINGERPRINTING PATTERN OF MANGROVE AVICENNIA MARINA
}

\author{
VINARS DAWANE, M. H. FULEKAR* \\ School of Environment and Sustainable Development, Central University of Gujarat, Gandhinagar 382030, Gandhinagar, Gujarat, India \\ Email: mhfulekar@yahoo.com
}

Received: 05 Dec 2016 Revised and Accepted: 14 Feb 2017

\begin{abstract}
Objective: An attempt has been made to study phytoconstituents and High-Performance Thin Layer Chromatography (HPTLC) fingerprinting pattern of leaf/stem/root methanol extracts of Avicennia marina.
\end{abstract}

Methods: The phytochemical screening was done by standard biochemical methods and standard optimized HPTLC densitometry determination was performed under two different energy zones [under UV-254 nm and under $540 \mathrm{~nm}$ after derivatization at sample size-10 $\mu \mathrm{l}$, temperature $=$ $25.8 \pm 0.3^{\circ} \mathrm{C}$ (constant) and relative humidity $=86 \pm 1 \%$ (constant) in optimized solvent system].

Results: Phytochemical analysis confirmed the presence of phytochemicals in the leaf, stem, and root of the plant. Under UV-254 nm energy range, the leaf, stem and root extract showed the presence of 8,6 and 5 components respectively and under $540 \mathrm{~nm}$ energy zone after derivatization, the leaf, stem and root extract revealed the presence of 7, 5 and 5 components, respectively and specific marker components with very high concentration (under UV-254 nm; 3, 2, 2 in leaf, stem, and root respectively and under $540 \mathrm{~nm}$ after ASR treatment; 2, 1, 2 in leaf, stem, and root respectively) were detected among them.

Conclusion: The preliminary phytochemical test results elucidated Avicennia marina leaf, stem, and root as a hug reservoir of various class of phytochemicals and metabolites. The results obtained by HPTLC fingerprinting method found to be acceptable as a quick, reliable, accurate and economical for identification and authentication of Avicennia marina mangrove plant and useful to differentiate this mangrove species from other similar mangroves, in a single TLC plate run. This serves as a biochemical marker pattern for leaf, stem and root parts of this mangrove and for its diverse phytoconstituents.

Keywords: Avicennia marina, Extracts, HPTLC fingerprinting, Marker compounds, Phytochemicals

(c) 2017 The Authors. Published by Innovare Academic Sciences Pvt Ltd. This is an open access article under the CC BY license (http://creativecommons.org/licenses/by/4. 0/) DOI: http://dx.doi.org/10.22159/ijpps.2017v9i4.16480

\section{INTRODUCTION}

The proper identification of medicinal plants, especially for mangroves, have been very important, especially in the fields of botany, taxonomical analysis, chemosystematics, Pharmacognosy, medicinal use and herbal drug quality control [1-2]. There are very few proper checklists of mangrove species, available from different regions of the world [2]. Mangroves are always being a precious source of unique biochemical substances and having a wider ethnic medicinal importance and biochemically uniqueness [3]. This assigns mangrove's noteworthy roles in the arena of natural product research and remedy detection since ancient times as crude or extracts or formulations [4], but plant reference chemicals possess a multifarious nature in their biochemical configurations, unknown chemical compositions and natural variability (quantitative and qualitative) allow them to differ noticeably and difficult to assess [5]. The specific environmental factors (like geography and place to place variations, physiology of the plant, its habitat, different soil composition and salinity levels, time of harvesting, levels of specific pollution and seasonal variations) and several other factors [5-6] found to be extremely influencing factors for phytoconstituents types and quantity existence in the plants [7-8]. The presence of other chemicals and impurities in the form of singularity or mixtures or multipart-motifs, also make it difficult to obtain a characteristic profile of a particular plant or its drug and also create many problems in standardisation of the drugs from the plant origin [9-10]. The existence of the botanical reference materials or working standard materials has also been very inadequate in the case of plants [11]. For these reasons, it is very difficult for herbal extract/formulation to meet its verification, fulfil existing regulatory issues and further economic viewpoint along with achieving drug excellence standards like WHO, FAO etc. [11-13]. To solve these issues and convert botanical materials into remedies, it has been essential and desirable to stabilize the whole existing chemical profile or detectable compounds pattern of the plant and produce an equilibrium between the number/type/amount of compounds [11, 14-15].

Avicennia marina is an important and valuable mangrove plant because of its diverse distribution, rich availability and massive medicinal values of its different plant parts [16]. The Avicennia marina possess various pharmacological and bioactive activities including anticancer [17-19], antimalarial [20-22], anti-inflammatory [23-24], antiviral [25-26], antioxidant [27-29], antibacterial [20-32], antifungal [33-35], herbal immunostimulant [36] and various protective effects [37] etc., made this mangrove a traceable source for already exist phytochemicals as well as new drug discovery in herbal treatment systems for various disease prevention. Apart from their plentiful uses in several disease treatments and ethnomedicinal worth and practicality, the chromatographies HPTLC pattern analysis or optimized fingerprint of Avicennia marina leaf, stem and root has not been fully reported yet and still very little is known related to whole Phytochemistry of its different plant parts.

The objective of this study was to provide simplest, cheapest and fastest HPTLC method, which was not available till the date for standardisation of Avicennia marina leaf, stem, and root methanol extracts. The present study will serve as an initial platform and a basis for its accurate botanical identity check, visual detection of its well-separated phytocompounds and authenticated use in disease treatment. The ease of sample preparation, quickness of this optimized fingerprinting method, uniformity of the generated results, the cheapness of the method and a single plate run for leaf/stem/root part assessment are the major novelty of this study.

\section{MATERIALS AND METHODS}

\section{Collection and identification}

The Avicennia marina [sub species (Forsk.)Vierh.] leaf, stem, and root was collected in January 2014 from the S. P. Godrej Marine 
Ecology Centre, Vikhroli, Mumbai city of Maharashtra, India (Geographical coordinates $19^{\circ} 05^{\prime} 50.82^{\circ} \mathrm{N}-72^{\circ} 56^{\prime} 24.06{ }^{\circ} \mathrm{E}$ ). The mangrove identification and authentication certificate issued by the same institute (the herbarium is maintained in the School of Environment and Sustainable Development, Central University of Gujarat voucher CUG/SESD/14/001).

\section{Extraction of plant material}

The leaf, stem, and root were shed dried for $30 \mathrm{~d}$ and grounded by a mechanical grinder. The $500 \mathrm{mg}$ of leaf/stem/root powder was mixed with $10 \mathrm{ml}$ methanol separately. Extracts were sonicated for $4 \mathrm{~h}$ until the extracts were clear or colorless. Direct sunlight and the high temperature was avoided to keep heat-sensitive phytochemicals and finally filtered through Whatman No.1 filter [11].

\section{Chemicals and reagents}

All chemicals were of analytical grade and solvents used were of HPLC grade, obtained from E-Merck (Mumbai, India). The plates were TLC aluminium plates precoated with silica gel $60 \mathrm{~F}_{254}(20 \mathrm{X} 10$ $\mathrm{cm}, 0.2 \mathrm{~mm}$ thick) batch number-1.05554.0007 obtained from E. Merck Ltd. (Darmstadt, Germany).

\section{Phytochemical screening}

Preliminary phytochemical analysis was performed for assessing the phytochemicals (phenols, alkaloids, terpenoids, steroids, carbohydrates, proteins, amino acids, tannins, saponins, and flavonoids, Gums, and Mucilage) present in the leaf, stem and root extracts according to the standard methods [38-39].

\section{HPTLC fingerprinting}

\section{Equipment}

CAMAG HPTLC system was used along with Linomat V as TLC sampler, TLC scanner 3 for HPTLC densitometry, REPROSTAR 3 for photo documentation analysis and winCATS-4 CAMAG Planer Chromatography software.

\section{HPTLC method}

Optimised HPTLC studies were performed by following Reich and Schibli [11] and Wagner et al., [5] guidelines. The sample solutions preparation protocols were optimised for great quality and precise fingerprinting. Sample extracts were applied to a volume of $2 \mu \mathrm{l}, 5 \mu \mathrm{l}$, $10 \mu \mathrm{l}$ and $20 \mu \mathrm{l}$ of each sample (leaf, stem, and root) as bands length of $8 \mathrm{~mm}$ wide by means of CAMAG Linomat V sample applicator armed with a $100 \mu \mathrm{l}$ syringe on a $20 \times 10 \mathrm{~cm}$ TLC plate. The plate prewash was done with methanol and dried in an oven at $60{ }^{\circ} \mathrm{C}$ for $10 \mathrm{~min}$. The samples loaded plate was kept in TLC Twin Trough horizontal Chamber $(20 \times 10 \mathrm{~cm})$ for $20 \mathrm{~min}$. saturation with the vapor of used solvent system. The patterns were developed in a linear ascending mode up to $80 \mathrm{~mm}$ (hardly in $10 \mathrm{~min}$.).

The mobile phase $\mathrm{C}_{6} \mathrm{H}_{5} \mathrm{CH}_{3}: \mathrm{CHCl}_{3}: \mathrm{C}_{2} \mathrm{H}_{5} \mathrm{OH}$ (4:4:1) was optimized and used [11]. After development, the plate was subjected to drying by hot air device, followed by $10 \mathrm{~min}$ on CAMAG plate heater $(110$ ${ }^{\circ} \mathrm{C}$ ) at room temperature and observed thanks to a Reprostar 3 illumination unit. The images captured under $254 \mathrm{~nm}$ (high UV range), $366 \mathrm{~nm}$ (Fluorescence) and $540 \mathrm{~nm}$ (White light). Then first densitometry evaluations were carried out under UV-254 nm (Deuterium lamp, high energy zone). In the last step the plate was derivatizing with a specific derivatizing agent for visual identification and in this experiment, the derivatizing agent Anisaldehyde Sulphuric Acid reagent (ASR) was used in the CAMAG derivatization chamber for 6-8 seconds and air dried. After drying, the plate was heated on CAMAG plate heater for $7-10 \mathrm{~min}$ at $110^{\circ} \mathrm{C}$ until the color bands can be seen visually. Final images were quickly captured under visible white light and fluorescence (366 nm). After that, second densitometry evaluations were carried out at $540 \mathrm{~nm}$ (white light, under tungsten lamp).

\section{RESULTS}

\section{Preliminary phytochemical test results}

The phytochemical studies (major classes secondary metabolites) by standard bioassays revealed the presence of phenolics, flavonoids, tannins, alkaloids, glycosides, carbohydrates, steroids, terpenoids and saponins in the methanol stem extract, while gums and mucilage and proteins and amino acids were found to be absent. In the methanol leaf extract, almost secondary classes of compounds were detected while saponins, gums and mucilage and proteins and amino acids were found to be absent. In the methanol extract of root, alkaloids, gums and mucilage and proteins and amino acids were not detected while all other major phytochemical class of phyto constitutes was found to be present (see table 1).

Table 1: Preliminary phytochemical test results of Avicennia marina leaf, stem, and root

\begin{tabular}{|c|c|c|c|c|c|}
\hline S. No. & Phytochemical & Test name & Leaf & Stem & Root \\
\hline 1 & Phenols & Folin-Ciocalteu reagent test & $(+)$ & $(+)$ & $(+)$ \\
\hline 2 & Flavonoids & Shenoda test & $(+)$ & $(+)$ & $(+)$ \\
\hline \multirow[t]{3}{*}{3} & Alkaloid & Mayer's test & $(+)$ & $(+)$ & $(-)$ \\
\hline & & Wagnor's test & $(+)$ & $(+)$ & $(-)$ \\
\hline & & Dragondroff's test & $(+)$ & $(-)$ & $(+)$ \\
\hline 4 & CardialGlycosides & Keiler-Killani test & $(+)$ & $(+)$ & $(+)$ \\
\hline 5 & Anthraquenones Glycosides & Borntrager's test & $(+)$ & $(+)$ & $(+)$ \\
\hline 6 & Tannins & $\mathrm{FeCl}_{3}$ test & $(+)$ & $(+)$ & $(+)$ \\
\hline 7 & Terpenoids & Noller's test & $(+)$ & $(+)$ & $(+)$ \\
\hline 8 & Steroids & Libermann's test & $(+)$ & $(+)$ & $(+)$ \\
\hline 9 & Saponins & Foam test & $(-)$ & $(+)$ & $(+)$ \\
\hline 10 & Carbohydrates & Fehling's test & $(+)$ & $(+)$ & $(+)$ \\
\hline 11 & Gums and Mucilage & Swelling test & $(-)$ & $(-)$ & $(-)$ \\
\hline 12 & Proteins and amino acids & Ninhydrin test & $(-)$ & $(-)$ & $(-)$ \\
\hline
\end{tabular}

+indicating positive test and-indicating negative test

\section{HPTLC photo documentation results}

HPTLC fingerprinting of three different extracts was studied by using the optimised mobile phase $\mathrm{C}_{6} \mathrm{H}_{5} \mathrm{CH}_{3}: \mathrm{CHCl}_{3}: \mathrm{C}_{2} \mathrm{H}_{5} \mathrm{OH}(4: 4: 1)$. The developed TLC plates were photo documented under UV-254 $\mathrm{nm}, \mathrm{UV}-366 \mathrm{~nm}$ and white light along with UV-366 nm after derivatization with ASR and is shown in the fig. 1 (A, B, C, and D).

\section{HPTLC scanning results (under UV-254 nm)}

The HPTLC densitogram under UV-254 nm of three extracts revealed several peaks which are presented in fig. 2.
The densitometry results of leaf extract for $10 \mu \mathrm{l}$ sample size, under UV-254 nm (high energy zone) revealed 8 spots with Rf max values (fig. 3 and table 2).

Three major spots with the Rf max $0.23,0.41$ and 0.44 may be principal components or marker compounds of leaf extract along with the percentage area of 24.60, 20.75 and 21.76 respectively.

Other spots are minor with the Rf $\max 0.10,0.15,0.32,0.55$ and 0.67 along with the percentage area of $10.26,4.16,8.66,5.80$ and 4.01 respectively (table 2). 


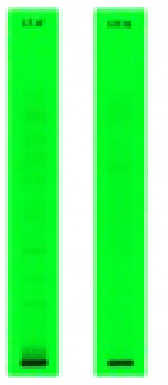

(A)

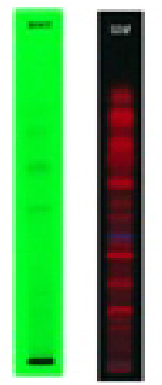

(B)

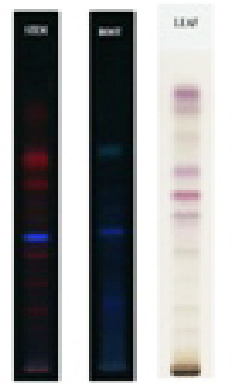

(C)

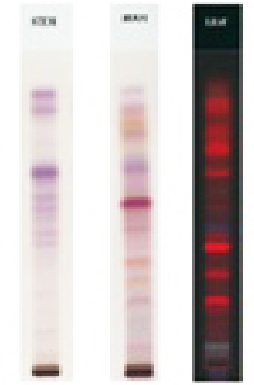

(D)

Fig. 1: The fig. of developed TLC plates under UV-254 nm (A) and UV-366 nm (B), under white light after derivatization with ASR (C) and under UV-366 nm after ASR (D) for $10 \mu \mathrm{l}$ sample size

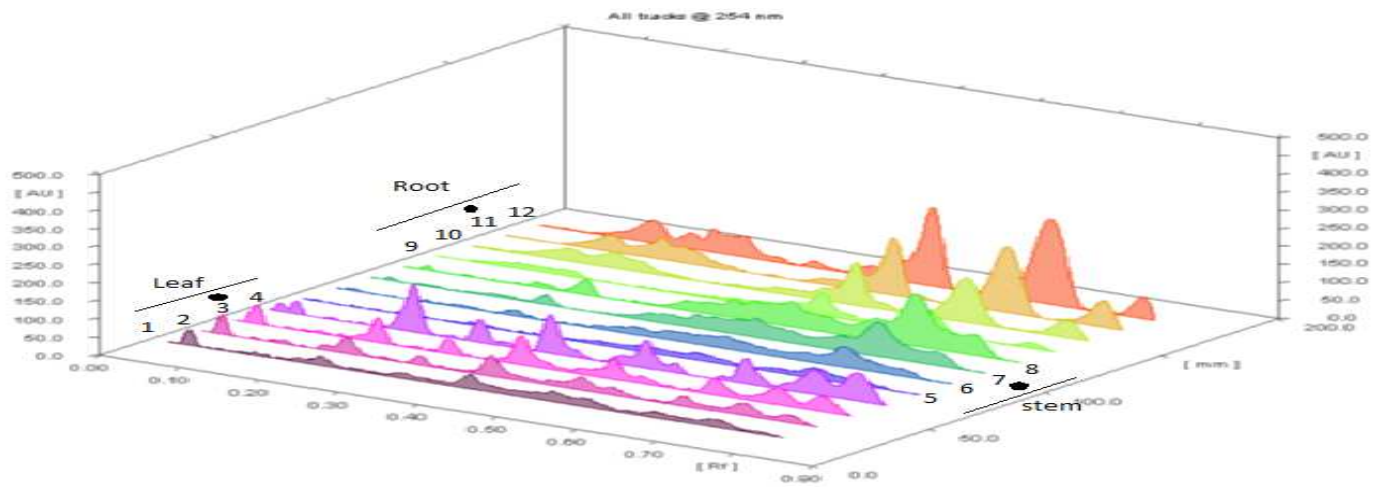

Fig. 2: The fig. of densitogram results of developed TLC plate under UV-254 nm. Densitogram was showing $2 \mu \mathrm{l}, 5 \mu \mathrm{l}, 10 \mu \mathrm{l}$ and $20 \mu \mathrm{l}$ scanning results of leaf (track $1,2,3,4)$, stem (track $5,6,7,8)$ and root $(9,10,11,12)$ extracts respectively from left to right, while the star pointed tracks (track 3, 7, 11 for leaf, stem, and root respectively) were standard optimized $10 \mu \mathrm{l}$ sample volume tracks which were used for final densitogram studies for fingerprinting method development

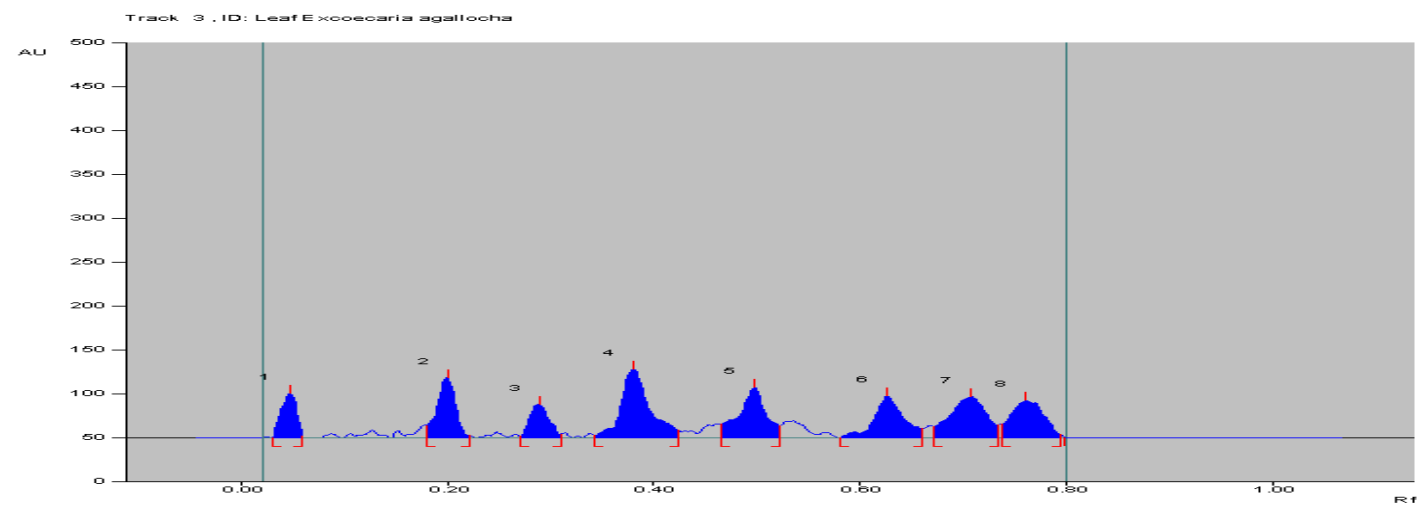

Fig. 3: HPTLC chromatogram of leaf extract has been shown under UV-254 $\mathrm{nm}$ wavelength

Table 2: Number of detected peaks, their corresponding $\mathrm{Rf}$ max values, height-area calculation results of leaf extract

\begin{tabular}{|c|c|c|c|c|c|c|}
\hline Track No. & Peak No. & Rf max & Max Height(AU) & $\operatorname{Max} \%$ & Area (AU) & Area \% \\
\hline 3 & 1 & .10 & 92.1 & 15.10 & 1691.2 & 10.26 \\
\hline 3 & 2 & .15 & 39.3 & 06.45 & 686.6 & 04.16 \\
\hline 3 & 3 & .23 & 145.4 & 23.84 & 4056.5 & 24.60 \\
\hline 3 & 4 & .32 & 34.0 & 05.58 & 1427.5 & 08.66 \\
\hline 3 & 5 & .41 & 96.2 & 15.78 & 3421.5 & 20.75 \\
\hline 3 & 6 & .44 & 123.8 & 20.30 & 3588.8 & 21.76 \\
\hline 3 & 7 & .55 & 54.4 & 08.92 & 956.2 & 05.80 \\
\hline 3 & 8 & .67 & 24.6 & 04.04 & 661.6 & 04.01 \\
\hline
\end{tabular}




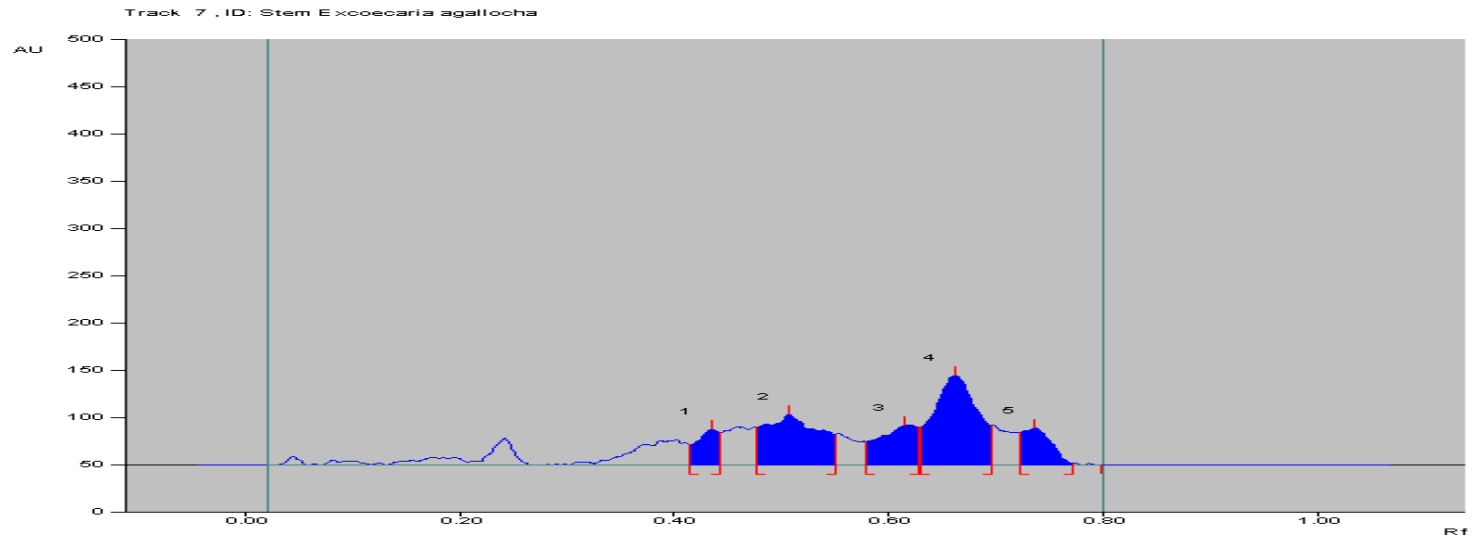

Fig. 4: HPTLC chromatogram of stem extract has been shown under UV-254 nm wavelength

The densitometry results of stem extract for $10 \mu \mathrm{l}$ sample size, under UV-254 nm (high energy zone) revealed the presence 6 spots with Rf max values (fig. 4 and table 3). Among these 6 detected spots, 2 spots with the Rf max 0.41 and 0.45 may be principal components of stem extract along with the very high percentage area of 24.32 and 39.31 respectively. Other detected 4 major peaks are minor with the Rf max $0.15,0.25,0.32$ and 0.70 along with the percentage area of $7.03,6.39,12.84$ and 10.10 respectively (table 3 ).

Table 3: Number of detected peaks, their corresponding $\mathrm{Rf}$ max values, height-area calculation results of stem extract

\begin{tabular}{|c|c|c|c|c|c|c|}
\hline Track No. & Peak No. & Rf Max & Max Height (AU) & Max \% & Area (AU) & Area \% \\
\hline 7 & 1 & .15 & 29.7 & 8.26 & 769.7 & 7.03 \\
\hline 7 & 2 & .25 & 31.7 & 8.82 & 699.6 & 6.39 \\
\hline 7 & 3 & .32 & 43.7 & 12.16 & 1405.6 & 12.84 \\
\hline 7 & 4 & .41 & 87.8 & 24.44 & 2662.4 & 24.32 \\
\hline 7 & 5 & .45 & 129.2 & 35.96 & 4303.1 & 39.31 \\
\hline 7 & 6 & .70 & 37.2 & 10.36 & 1105.8 & 10.10 \\
\hline
\end{tabular}

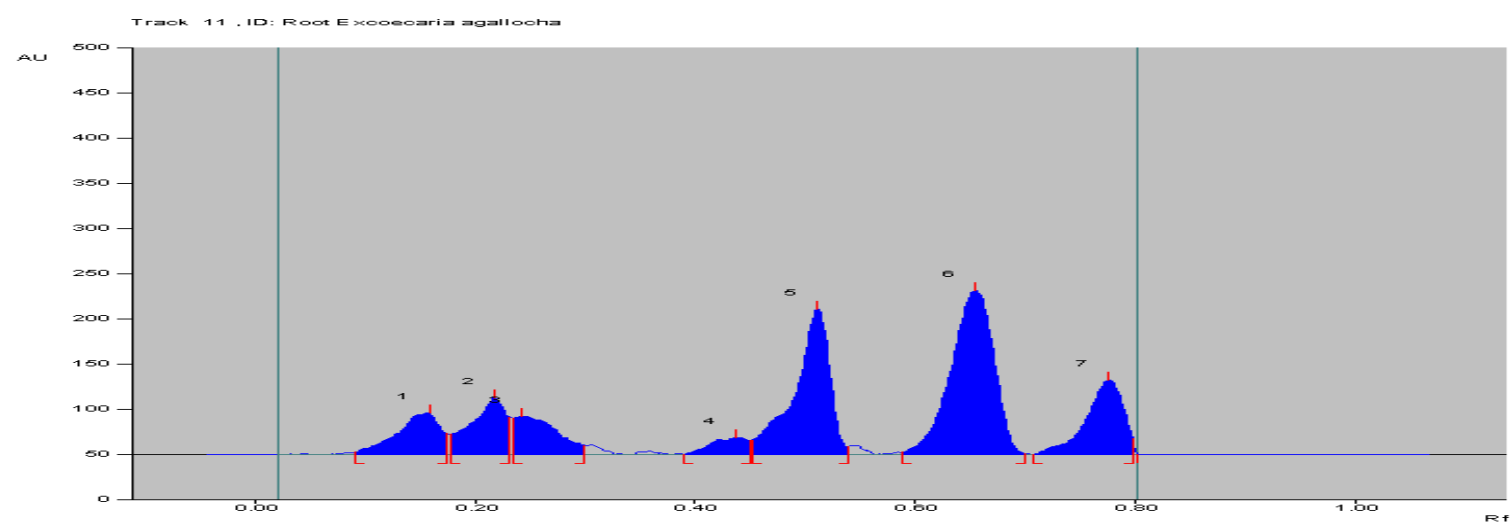

Fig. 5: HPTLC chromatogram of root extract has been shown under UV-254 nm wavelength

The densitometry results of root extract for $10 \mu \mathrm{l}$ sample size, under UV-254 nm (high energy zone) revealed the presence 5 spots with Rf max values (fig. 5 and table 4). Among all 5 detected peaks, 2 spots (spot no. 3 and 5) the corresponding Rf max 0.36 and 0.47 may be principal components of root extract because they contain comparatively the very high percentage area of 21.22 and 48.24 respectively. Other peaks contain very less percentage area of 6.28 , 9.29 and 14.97 along with $\mathrm{Rf} \max 0.07,0.17$ and 0.42 respectively.

Table 4: Number of detected peaks, their corresponding $\mathrm{Rf}$ max values, height-area calculation results of root extract

\begin{tabular}{|c|c|c|c|c|c|c|}
\hline Track No. & Peak No. & Rf max & Max Height (AU) & Max \% & Area (AU) & Area \% \\
\hline 11 & 1 & .07 & 56.7 & 16.00 & 573.5 & 6.28 \\
\hline 11 & 2 & .17 & 42.8 & 12.08 & 847.9 & 9.29 \\
\hline 11 & 3 & .36 & 64.2 & 18.13 & 1936.4 & 21.22 \\
\hline 11 & 4 & .42 & 67.0 & 18.92 & 1365.9 & 14.97 \\
\hline 11 & 5 & .47 & 123.6 & 34.87 & 4402.3 & 48.24 \\
\hline
\end{tabular}


HPTLC scanning results (Under $540 \mathrm{~nm}$ (white or visible light) after derivatization with ASR

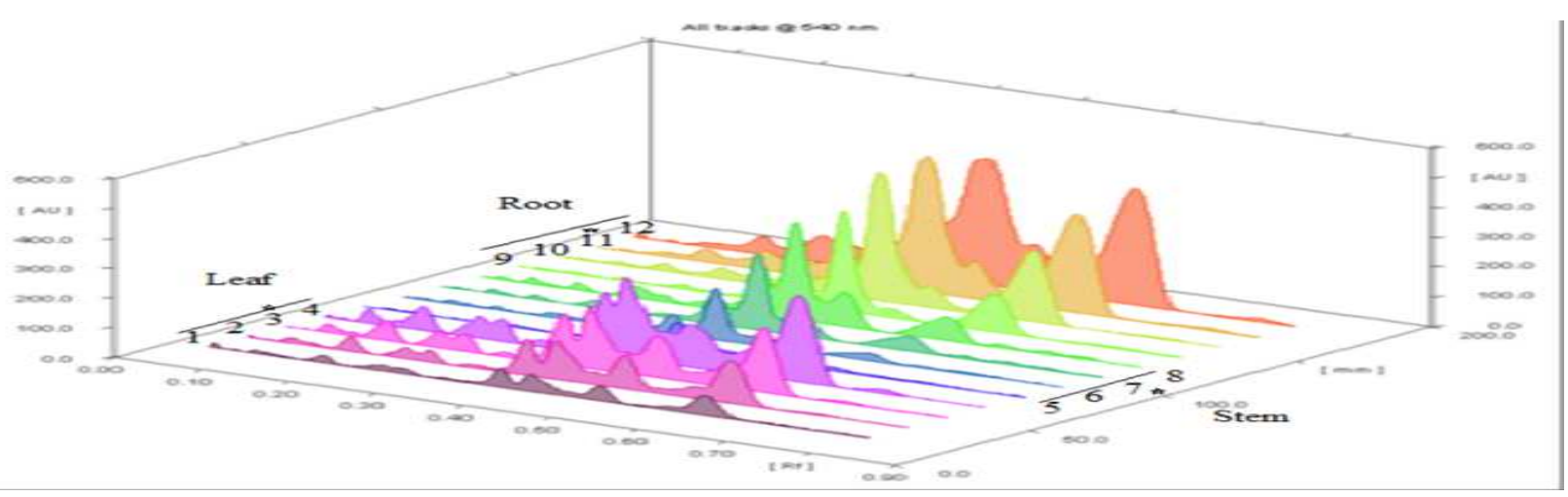

Fig. 6: The fig. of densitogram results of developed TLC plate under $540 \mathrm{~nm}$ after derivatization with ASR. Densitogram was showing $2 \mu \mathrm{l}$, $5 \mu \mathrm{l}, 10 \mu \mathrm{l}$ and $20 \mu \mathrm{l}$ scanning results of leaf (track 1,2,3,4), stem (track 5,6,7,8) and root $(9,10,11,12)$ extracts respectively from left to right, while the star pointed tracks (track 3, 7, 11 for leaf, stem, and root respectively) were standard optimized $10 \mu$ l sample volume tracks which were used for final densitogram studies for fingerprinting method development

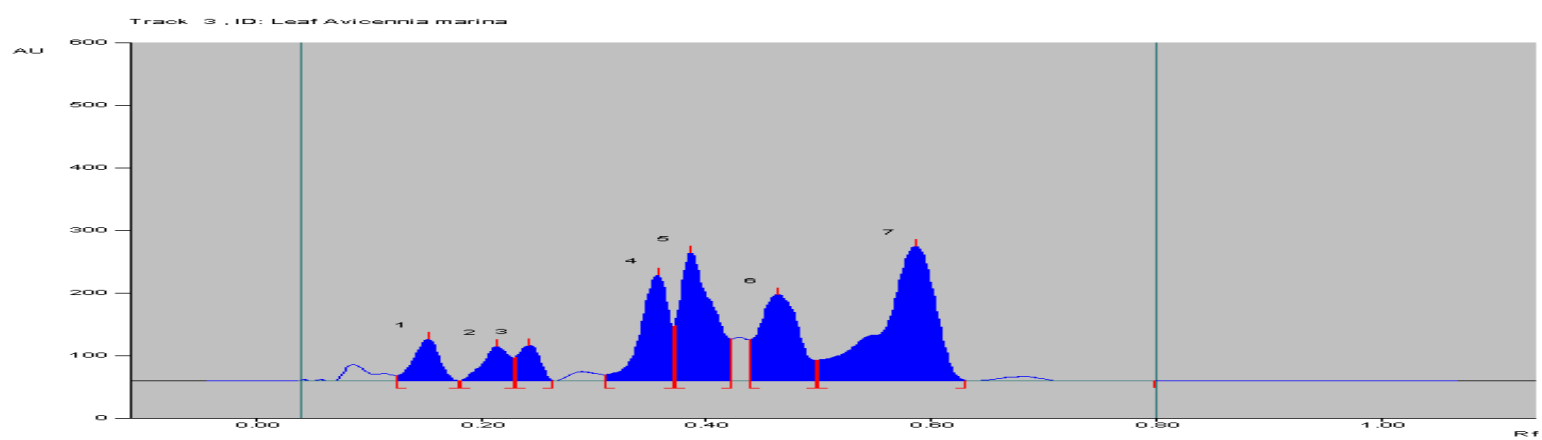

Fig. 7: HPTLC chromatogram of leaf extract has been shown under $540 \mathrm{~nm}$ wavelength light after ASR treatment

The densitometry results of leaf extract for $10 \mu \mathrm{l}$ sample size, under $540 \mathrm{~nm}$ (after ASR) revealed the presence 7 spots with $\mathrm{Rf}$ max values (fig. 7 and table 5). Among all 7 detected peaks, 2 spots (spot no. 5 and 7 ) the corresponding Rf max 0.37 and 0.50 possess comparatively high percentage area of 20.46 and 35.25 respectively (may be the marker compounds or active principle). Other peaks with $\operatorname{Rf} \max 0.13,0.18,0.23,0.31$ and 0.44 were minor (table 5).

Table 5: Number of detected peaks, their corresponding Rf max values, height-area calculation results of leaf extract under 540 nm after ASR treatment

\begin{tabular}{|c|c|c|c|c|c|c|}
\hline Track No. & Peak No. & Rf max & Max height (AU) & Max \% & Area (AU) & Area \% \\
\hline 3 & 1 & .13 & 66.7 & 7.36 & 1219.3 & 5.11 \\
\hline 3 & 2 & .18 & 55.0 & 6.06 & 1069.4 & 4.48 \\
\hline 3 & 3 & .23 & 56.9 & 6.28 & 892.3 & 3.74 \\
\hline 3 & 4 & .31 & 169.7 & 18.72 & 3418.7 & 14.34 \\
\hline 3 & 5 & .37 & 204.9 & 22.61 & 4880.1 & 20.46 \\
\hline 3 & 6 & .44 & 138.2 & 15.24 & 3962.8 & 16.62 \\
\hline 3 & 7 & .50 & 215.1 & 23.73 & 8405.9 & 35.25 \\
\hline
\end{tabular}

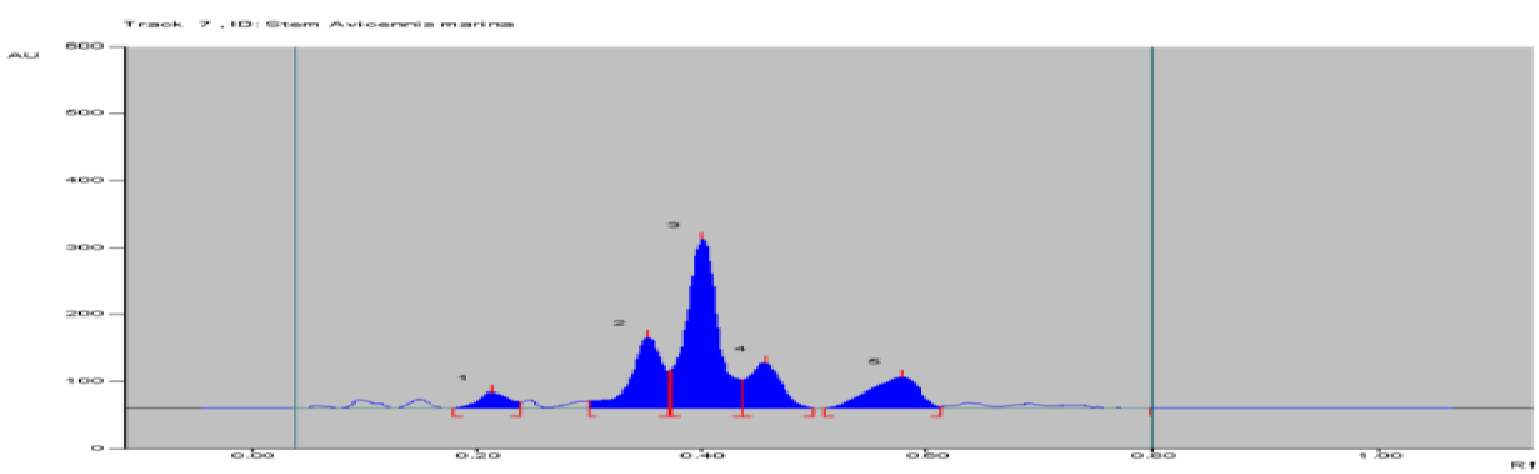

Fig. 8: HPTLC chromatogram of stem extract has been shown under $540 \mathrm{~nm}$ wavelength light after ASR treatment 
The densitometry results of stem extract for $10 \mu \mathrm{l}$ sample size, under $540 \mathrm{~nm}$ (after ASR) revealed the presence 5 spots with Rf max values (fig. 8 and table 6). Among all 5 detected peaks, 1 spot (spot no. 3) the corresponding $\mathrm{Rf} \max 0.40$ contain comparatively very high percentage area of 47.40 (may be the marker compounds or active principle).

Other peaks with $\mathrm{Rf} \max 0.22,0.35,0.46$ and 0.58 were minor (table 6).

Table 6: Number of detected peaks, their corresponding Rf max values, height-area calculation results of stem extract under $540 \mathrm{~nm}$ after ASR treatment

\begin{tabular}{|c|c|c|c|c|c|c|}
\hline Track No. & Peak No. & Rf max & Max Height(AU) & Max \% & Area (AU) & Area \% \\
\hline 7 & 1 & .22 & 23.7 & 4.78 & 533.2 & 4.44 \\
\hline 7 & 2 & .35 & 106.1 & 21.39 & 2403.0 & 19.99 \\
\hline 7 & 3 & .40 & 251.7 & 50.75 & 5698.9 & 47.40 \\
\hline 7 & 4 & .46 & 67.5 & 13.60 & 1665.2 & 13.85 \\
\hline 7 & 5 & .58 & 47.0 & 9.47 & 1721.7 & 14.32 \\
\hline
\end{tabular}

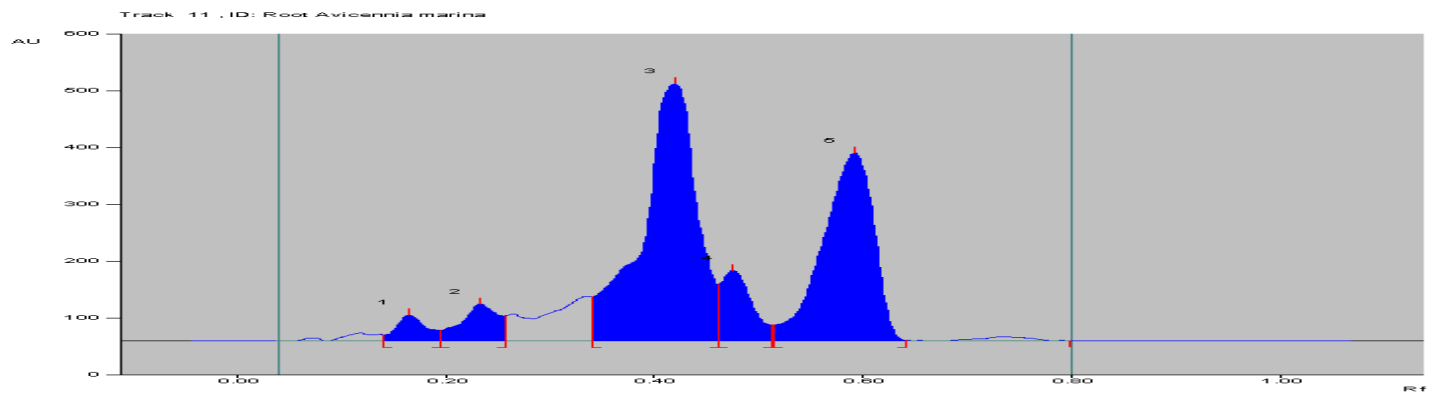

Fig. 9: HPTLC chromatogram of root extract has been shown under $540 \mathrm{~nm}$ wavelength light after ASR treatment

The densitometry results of root extract for $10 \mu \mathrm{l}$ sample size, under $540 \mathrm{~nm}$ (after ASR) revealed the presence 5 spots with $\mathrm{Rf}$ max values (fig. 9 and table 8). Among all 5 detected peaks, 2 spots (spot no. 3 and 5) the corresponding Rf max 0.42 and 0.59 possess comparatively very high percentage area of 50.21 and 34.40 respectively (may be the marker compounds or active principle). Other peaks with $\mathrm{Rf} \max 0.17,0.23$ and 0.48 were minor (table 7).

Table 7: Number of detected peaks, their corresponding $\mathrm{Rf}$ max values, height-area calculation results of root extract under $540 \mathrm{~nm}$ after ASR treatment

\begin{tabular}{|c|c|c|c|c|c|c|}
\hline Track No. & Peak No. & Rf max & Max height (AU) & Max \% & Area (AU) & Area \% \\
\hline 11 & 1 & .17 & 45.4 & 4.45 & 1085.6 & 2.79 \\
\hline 11 & 2 & .23 & 65.2 & 6.40 & 1917.5 & 4.94 \\
\hline 11 & 3 & .42 & 452.8 & 44.48 & 19508.2 & 50.21 \\
\hline 11 & 4 & .48 & 123.8 & 12.16 & 2977.2 & 7.66 \\
\hline 11 & 5 & .59 & 331.0 & 32.51 & 13364.1 & 34.40 \\
\hline
\end{tabular}

\section{DISCUSSION}

In this outlook of plant standardization and authentic pharmacological usages, HPTLC fingerprinting is although comparatively new concept and technique but a critical as well as indispensable benchmark [40] because from an optimized HPTLC fingerprint of a plant species one can gain the whole spectrum of information about the sample and can recognise the "Unique Total Component Arrangements" as well as it can act as "Biochemical Autograph" or "phytochemical principle component's representative" of particular herbal sample [11].

It allows us to achieve fundamental requirements for ethanobotanical use of plants in various traditional folk systems (ex. Asian folk systems like Indian and Chinese, etc.) [41].

Here HPTLC method and various HPTLC parameters were optimized to gain a characteristic fingerprint of leaf, stem, and root of Avicennia marina in a single HPTLC plate run. The mobile phase which was optimized for this study was also previously used in some very recent studies related to the characterization and analysis the phytochemistry of medicinal plants [42-43], comparison of HPTLC pattern assessment of plants [44-45] also with slightly modifications in selected mobile phase [46], study the autograph and drug formulation [47] as well as quantification of specific bioactive compound [48] and produce fingerprints [49]. Here this mobile phase gave very reasonable Rf and resolution of the separated bands and capable of generating a specific fingerprint for leaf, stem, and root parts of this mangrove separately in a quick/single run. With very high concentration and area calculation various principle components (under UV-254 nm; 3, 2, 2 in leaf, stem, and root respectively and under $540 \mathrm{~nm}$ after ASR treatment; 2, 1, 2 in leaf, stem, and root respectively) were detected. These may be the marker compounds of corresponding samples.

Most of time many factors (especially the sample volume and the detection limit of compounds etc.) become a critical factor to study and generate a chromatographic method for different chromatographic techniques [50-52] like an optimised HPTLC patterns [38] or quantification of bioactive compound [53] as well as isolation-characterization studies by preparative HPTLC [54], thus $10 \mu \mathrm{l}$ sample volume was optimised for reproducible and accurate pattern generation and assessment among $2 \mu \mathrm{l}, 5 \mu \mathrm{l}, 10 \mu \mathrm{l}$ and $20 \mu \mathrm{l}$ sample volume size.

This sample volume size can provide us valuable information related to the number of compounds and also facilitate equilibrium between the various categories of phytocompounds present in the extracts [11]. 


\section{CONCLUSION}

The results achieved from preliminary phytochemical bioassay studies and HPTLC fingerprinting will be helpful to assess and understand the rich phytochemical scenario of Avicennia marina mangrove. This optimized HPTLC pattern assessment method can be useful in the identification of this species, its various phytocompounds as well as its different plant parts (leaf/stem/root) in a single TLC plate experiment and can ensure quality control of the drugs obtained.

This optimized HPTLC method for Avicennia marina leaf, stem and root found to be unique, innovative, exact for its kind and usable as a reference. The Avicennia marina leaf, stem and root methanol extracts showed the presence of 8,5 and 6 UV active spots respectively (under UV-254 $\mathrm{nm}$ ) and 7, 5 and 5 respectively (under $540 \mathrm{~nm}$ after ASR) at sample size- $10 \mu \mathrm{l}$, Temperature $=25.8 \pm 0.3{ }^{\circ} \mathrm{C}$ (constant), Relative Humidity $=86 \pm 1 \%$ (constant) and mobile phase $=\mathrm{C}_{6} \mathrm{H}_{5} \mathrm{CH}_{3}: \mathrm{CHCl}_{3}: \mathrm{C}_{2} \mathrm{H}_{5} \mathrm{OH}$ (4:4:1). This characteristic and optimized HPTLC fingerprinting method for Avicennia marina leaf, stem and root found to be fast, inexpensive, accurate and a consistent fingerprinting method for the identification, verification and quality regulation of drugs from this mangrove species. It can also provide the basic information useful for the isolation and purification of existing or new bioactive compounds.

\section{ACKNOWLEDGEMENT}

The authors are grateful to Soonabai Pirojsha Godrej Marine Ecology Centre, Mumbai for Avicennia marina sample collection and also thankful to ANCHROM HPTLC labs, Mumbai for providing HPTLC facilities during this research. Mr. Vinars Dawane is thankful to Prof. K. Kathiresan, CASMB, Annamalai University, Parangipettai, TN for providing the lab facilities for phytochemical characterization and valuable suggestions and UGC, New Delhi for the award of Rajiv Gandhi National Fellowship for financial support. Vinars Dawane is thankful to roomies Ankur katre, Sudhir khopey, Swapnil kulkarni and Sandeep singh for their unconditional friendship and support.

\section{CONFLICTS OF INTERESTS}

Both authors have none to declare

\section{REFERENCES}

1. Fabricant DS, Farnsworth NR. The value of plants used in traditional medicine for drug discovery. Environ Health Perspect 2001;109 Suppl 1:69-75.

2. Giesen W, Wulffraat S, Zieren M, Scholten L. Mangrove guidebook for southeast Asia, Dharmasarn Co., Ltd., FAO and Wetlands International; 2006. p. 4-7. Available from: ftp://ftp.fao.org/docrep/fao/010/ag132e/ag132e00.pdf. [Last accessed on 19 Nov 2016]

3. Bandarnayake WM. Traditional and medicinal uses of mangroves. Mangroves Salt Marshes 1998;2:133-48.

4. Bandarnayake WM. Bioactivities, bioactive compounds and chemical constituents of mangrove plants. Wetlands Ecol Manage 2002;10:421-52.

5. Wagner H, Baldt S, Zgainski EM. Plant drug analysis. $1^{\text {st }}$ ed. Berlin: Springer; 1996.

6. Monika WH, Joseph S, Teresa K. Thin layer chromatography in phytochemistry. Vol. 99 CRC Press: Taylor and Francis Group. London; 2008. p. 1-10.

7. Pavarini DP, Pavarini SP, Niehues M, Lopes NP. Exogenous influences on plant secondary metabolite levels. Anim Feed Sci Technol 2012;176:5-16.

8. Donaldson JR, Lindroth RL. Genetics, environment and their interaction determine the efficacy of chemical defence in trembling aspen. Ecology 2007;88:729-39.

9. Choudhary N, Sekhon BS. An overview of advances in the standardisation of herbal drugs. J Pharm Educ Res 2011;2:55-70.

10. Sahil K, Sudeep B, Akansha M. Standardization of medicinal plant materials. Int J Res Ayurveda Pharm 2011;2:1100-9.

11. Reich E, Schibli A. High-performance thin layer chromatography for the analysis of medicinal plants. $1^{\text {st }}$ ed. Thieme Medical Publishers, Inc., The Americans, NY; 2007.

12. Reich E, Schibli A. Validation of high-performance thin-layer chromatographic methods for the Identification of botanicals in a cGMP environment. J AOAC Int 2008;91:13-20.
13. WHO guidelines for assessing the quality of herbal medicines with reference to contaminants and residues. Available from: http://apps.who.int/medicinedocs/index/assoc/s14878e/s14 878e.pdf. [Last accessed on 19 Nov 2016]

14. Xie PS, Sun S, Xu S, Guo L. Value the unique merit of HPTLC image analysis and extending its performance by digitalization for herbal medicines quality control. J Chromatogr Sep-Tech 2014;5:1-9.

15. Xie $\mathrm{P}$, Chen $\mathrm{S}$, Liang $\mathrm{YZ}$, Wang $\mathrm{X}$, Tian $\mathrm{R}$, Upton $\mathrm{R}$. Chromatographic fingerprint analysis-a rational approach for quality assessment of traditional Chinese herbal medicine. J Chromatogr 2006;1112:171-80.

16. Ishrak K, Gab AA, Salama W, Fouda M. Biological activities and phytochemical constituents of the gray mangrove Avicennia marina (Forssk.) Vierh. Egyptian J-Biology 2003;5:62-9.

17. Sukhramani PS, Patel PM. Biological screening of Avicennia marina for anticancer activity. Der Pharm Sinica 2013; 4:125-30.

18. Huang $\mathrm{C}, \mathrm{Lu} \mathrm{CK}, \mathrm{Tu} \mathrm{MC}$, Chang JH, Chen YJ, Tu YH, et al. Polyphenol-rich Avicennia marina leaf extracts induce apoptosis in human breast and liver cancer cells and in a nude mouse xenograft model. Oncotarget 2016;7:1-20.

19. Das G, Gouda S, Mohanta YK, Petra JK. Mangrove plants: a potential source for anticancer drugs. Indian J Geo-Marine Sci 2015;44:1-7.

20. Renugadevi G, Ramanathan $T$, Shanmugapriya R, Thirunavukkarasu P. Studies on the combined effect of mangrove plants against three dangerous mosquitoes. Int J Pharm Biol Arch 2012;3:357-62.

21. Ravikumar S, Inbaneson SJ, Suganthi P, Venkatesan M, Ramu A. Mangrove plants as a source of lead compounds for the development of new antiplasmodial drugs from South East coast of India. Parasitol Res 2011;108:1405-10.

22. Khattab RM, Gaballa AA, Zakaria SM, Abdullah EL, Ali AE, Sallam IS. Larvicidal effect of crude extracts of some marine plants (mangrove and seagrasses) on mosquitoes of Culexpipiens. Egyptian J Aquatic Biol Fisheries 2012;16:99-105.

23. Gandomani MZ, Molaali EF, Gandomani ZZ, Madani H, Moshtaghian SJ. Evaluation of the anti-inflammatory effect of hydroalcoholic extract of mangrove (Avicennia Marina) leaves in male rats. Med J Tabriz University MedSci 2012;34:80-5.

24. Shafie MM, Forghani AH, Moshtaghiyan J. Anti-inflammatory effects of hydro-alcoholic extracts of mangrove (Avicennia marina) and vitamin C on arthritic rats. Bull Env Pharmacol Life Sci 2013;2:32-7.

25. Namazi R, Zabihollahi R, Behbahani M, Rezaei A. Inhibitory activity of Avicennia marina, a medicinal plant in persian folk medicine, against HIV and HSV. Iranian J Pharm Res 2013;12:435-43.

26. Zandi K, Taherzadeh M, Yaghoubi R, Tajbakhsh S, Rastian Z, Fouladvand $\mathrm{M}$, et al. Antiviral activity of Avicennia marina against herpes simplex virus type 1 and vaccine strain of poliovirus (An in vitro study). J Med Plants Res 2009;3:771-5.

27. Rout P, Basak UC. Antioxidant properties in leaf and root extracts of some medicinally important mangrove species of odisha coast. Am J Pharmatech Res 2014;4:606-17.

28. Thatoi HN, Patra JK, Das SK. Free radical scavenging and antioxidant potential of mangrove plants: a review. Acta Physiol Plant 2014;36:561-79.

29. Srikanth M, Rao BG, Talluri MR, Swamy TR. Abortifacient and antioxidant activities of Avicennia marina. Int Lett Nat Sci 2015;33:12-26.

30. Ravikumar S, Gnanadesigan M, Suganthi P, Ramalakshmi A. Antibacterial potential of chosen mangrove plants against isolated urinary tract infectious bacterial pathogens. Int J Med MedSci 2010;2:94-9.

31. Dhayanithi NB, Kumar TTA, Murthy RG, Kathiresan K. Isolation of antibacterials from the mangrove, Avicennia marina and their activity against multi-drug resistant Staphylococcus aureus. Asian Pacific J Trop Biomed 2012;2:1892-5.

32. Behbahani BA, Yazdi FT, Shahidi F, Mohebbi M. Antimicrobial activity of Avicennia marina extracts ethanol, methanol and 
glycerine against Penicillium digitatum (citrus green mold). Sci J Microbiol 2012;1:147-51.

33. Bobbarala V, Katikala PK, Naidu KC, Penumajji S. Antifungal activity of selected plant extracts against phytopathogenic fungi Aspergillusniger F2723. Indian J Sci Technol 2009;2:87-90.

34. Nayak BK, Janaki T, Ganesan T. Antimicrobial activity of Avicennia marina (Forsk) Vierh from Backwater area of Puducherry, India. Int J ChemTech Res 2014;6:4667-70.

35. Afzal M, Mehdi FS, Abbasi FM, Ahmad H, Masood R, Alam J, et al. Efficacy of Avicennia marina (Forsk.) Vierh. Leaves extracts against some atmospheric fungi. Afr J Biotechnol 2011; 10:1090-4.

36. Balachandran DN, Kumar TTA, Arockiaraj J, Balasundaram C, Harikrishnan R. Dietary supplementation of Avicennia marina extract on immune protection and disease resistance in Amphiprion sebae against Vibrio alginolyticus. Fish Shellfish Immunol 2015;45:52-8.

37. Mirazi N, Movassagh SN, Rafieian-Kopaei M. The protective effect of a hydro-alcoholic extract of mangrove (Avicennia marina L.) leaves on kidney injury induced by carbon tetrachloride in male rats. J Nephropathol 2016;5:118-22.

38. Khandelwal KR. Techniques and experiments, practical pharmacognosy. ed $17^{\text {th }}$. Nirali Prakashan, Pune; 2007. p. 149-56.

39. Evans WC. Trease and Evans Phamacognose. Ed. $14^{\text {th }}$. W. B. Saunders Company Limited, Singapore; 1998. p. 315-6.

40. Giri L, Andola HC, Purohit VK, Rawat MSM, Rawal RS, Bhatt ID. Chromatographic and spectral fingerprinting standardization of traditional medicines: an overview as modern tools. Res J Phytochem 2010;4:234-41.

41. Srivastava MM. High-performance thin layer chromatography; Springer Heidelberg Dordrecht London, New York; 2011.

42. Ghosh S, Derle A, Ahire M, More P, Jagtap S, Phadatare SD, et al. Phytochemical analysis and free radical scavenging activity of medicinal plants Gnidia glauca and Dioscorea bulbifera. PLoS One 2013;8:1-18.

43. Gore M, Desai NS. Characterization of phytochemicals and evaluation of the anti-cancer potential of Blumea eriantha DC. Physiol Mol Biol Plants 2014;20:475-86.

44. Asha D, Mathew L. Comparative HPTLC fingerprint profile of triterpenes in the methanolic extracts of Ocimum basilicum L. and Mentha arvensis L. (Lamiaceae). J Pharmacogn Phytochem 2014;3:171-5.
45. Patil GN. Phyto-chemical therapy for inhibition of fish pathogenic bacteria in sea-food and aquaculture. Int J Sci Eng Res 2012;3:1-7.

46. Dawane V, Pathak B, Fulekar MH. HPTLC pattern assessment of Avicennia marina stem and spectrometric analysis of the separated phytoconstituents. Biosci Biotechnol Res Commun 2016;9:114-20.

47. Prabhu P, Muralidhar M. Development and validation of a highperformance liquid chromatography method for simultaneous determination of irbesartan and its related impurities in pharmaceutical tablets. Int J Pharm Sci Drug Res 2014;6:145-53.

48. Dipal G, Mehta P. Validated high-performance thin-layer chromatographic method for the quantification of betulinic acid from two Indian plants of the species Dillenia and Ziziphus. J Planar Chromatography-Modern TLC 2013;26:331-5.

49. Sutar RC, Kasture SB, Kalaichelvan VK. Preliminary phytochemical screening and high-performance thin layer chromatography fingerprint profile of leaf extracts of holoptelea integrifolia (roxb.) planch. Asian J Pharma Clin Res 2014;7:94-7.

50. Virani P, Sojitra R, Raj H, Jain V. Chromatographic method for irbesartan and its combination with another drug. J Crit Rev 2015;31:7-11.

51. Kumar S, Sivakumar T, Kt A, Mythili N. GC-MS evaluation of bioactive phytochemicals of commercial green teas (Camellia sinensis) of India. Asian J Pharm Clin Res 2015;8:278-82.

52. Mohammad Y. A validated stability-indicating high performance liquid chromatographic method for simultaneous determination of metform in HCL and dapaglifloz in in bulk drug and tablet dosage form. Asian J Pharm Clin Res 2015; 8:320-6.

53. Dawane V, Fulekar MH. Quantification of lupeol in Excoecaria agallocha leaf, stem and root by HPTLC. Int Res J Biol Sci 2017;6:1-5.

54. Dawane V, Fulekar MH. Development of HPTLC methods for isolation and physical characterization of botanical reference material of Avicennia marina stem. Biosci Biotech Res Comm 2016;9:841-9.

\section{How to cite this article}

- Vinars Dawane, MH Fulekar. High-performance thin layer chromatography (HPTLC) fingerprinting pattern of mangrove avicennia marina. Int J Pharm Pharm Sci 2017;9(4):65-72. 